\title{
Assessment of Medical Waste Generation at a Medical Center in Keffi Metropolis
}

\author{
Useh Uwem Jonah ${ }^{1}$, Lawal Habiba Muda ${ }^{1}$, Useh Mercy Uwem², Etuk-Udo Godwin Akpan ${ }^{3}$, \\ Katampe Ibrahim ${ }^{4}$ \\ ${ }^{1}$ Department of Pollution Control, Ecological Fund Office, Abuja, Nigeria \\ ${ }^{2}$ Chemistry Advanced Research Centre, Sheda Science and Technology Complex (SHESTCO), Abuja, Nigeria \\ ${ }^{3}$ Biotechnology Advanced Research Centre, Sheda Science and Technology Complex (SHESTCO), Abuja, Nigeria \\ ${ }^{4}$ Department of Natural Sciences, Central State University, Ohio, United States of America
}

\section{Email address:}

uwem_useh@yahoo.com (U. U. Jonah)

\section{To cite this article:}

Useh Uwem Jonah, Lawal Habiba Muda, Useh Mercy Uwem, Etuk-Udo Godwin Akpan, Katampe Ibrahim. Assessment of Medical Waste Generation at a Medical Center in Keffi Metropolis. American Journal of Biological and Environmental Statistics.

Vol. 4, No. 1, 2018, pp. 31-41. doi: 10.11648/j.ajbes.20180401.15

Received: January 31, 2018; Accepted: February 16, 2018; Published: March 21, 2018

\begin{abstract}
Healthcare waste represents an important stream of pollutants that impacts on medical personnel and attendees of such facilities. This study examined the quantities of waste generated among 14 different wards and units at the federal medical center, Keffi in Nasarawa state, Nigeria. It also evaluated crucial factors that influence the selection of hospitals by patients as well as the methods employed in waste treatment. The results from the study revealed that an average volume ( $\mathrm{Kg} / \mathrm{bed} / \mathrm{day})$ of 1.97 (Accident \& Emergency), 2.27 (Male Medical), 1.71 (Female Medical), 1.79 (Female Surgical), 1.98 (Pediatric), 2.11 (Orthopedic), 1.91 (Lying-in), 1.42 (Amenity), 2.53 (Main theatre), 1.17 (Pediatric surgical), 0.41 (Intensive care unit), 2.03 (Pharmacy), 2.34 (Laboratory) and 4.82 (Labour room). It was established that infectious waste represented the highest rate of hazardous waste $(21.3 \%)$, while pathological $(18.0 \%)$, sharp objects $(15.8 \%)$ and pharmaceuticals $(11.4 \%)$ represented the sum total of the non-hazardous waste stream. Very strong correlations existed between the Male Medical Ward and Main Theatre $\left(\mathrm{r}_{\mathrm{s}}\right.$ 0.9), Female Medical and Female Surgical wards $\left(r_{s}\right.$ 0.94), Pediatric and Pediatric Surgical wards $\left(r_{s}\right.$ 0.90), Lying-in and Amenity wards $\left(r_{s} 0.88\right)$, Accident \& Emergency and Orthopedic units $\left(r_{s} 0.86\right)$, with strong correlation between the pharmacy and the laboratory $\left(r_{s} 0.65\right)$ and a moderate correlation between the intensive care unit and the Labour room $\left(r_{s} 0.46\right)$. The study showed that financial capability was the most important factor that influenced public decision on the choice of the medical center ranked 1, with a relative important index (RII) of 10 in the choice of facilities and methods used to manage waste generated. Other factors in order of importance were ownership of the medical center (2) with an RII of 9 with cultural and social bias ranked as 7 with an RII of 4 .
\end{abstract}

Keywords: Healthcare Waste, Wards and Units, Daily Rate

\section{Introduction}

Medical wastes emanating from different units within healthcare facilities across developing countries are of great importance owing to their potential public health risks and associated environmental hazards, particularly when inapt waste management techniques are employed [1], [2], [3], [4]. With an increasing population and use of healthcare facilities, the total waste flow of bio-hazardous, blood, corrosive, diagnostic samples, genotoxic, infectious, pharmaceutical, pathological and sensitizing wastes materials may overwhelm waste disposal and treatment facilities in developing countries [5], [6], [7], [8], [9]. Large quantities of medical waste, categorized as infectious and hazardous, particularly towards doctors, medical technicians, auxiliary hospital staff, hospital visitors and patients due to indiscriminate management and the environment [10], [11].

Like all other healthcare facilities globally, the generation of medical wastes varies, owing to factors like the specialization, number of hospital beds, seasonal variation, 
proportion of patients treated on a daily basis, etc [12]. To this end, quantification and assessment of the rate of medical waste generation has spurn the interest of several researchers, pollution control and environmental enthusiasts. Per capita medical waste generation measurements across developing nations in Europe was shown to increase by up to $8 \mathrm{~kg}$ per bed per day in countries like but not limited to Croatia, Cyprus, Denmark, France, Greece, Lithuania, Spain and United Kingdom [13], [14], [15]. Per capita waste generation permits the sourcing of adequate treatment modalities that suits the categories and volumes of healthcare wastes across developed and developing countries. However, in developing countries, the selection of adequate treatment facilities is harpooned by insufficient data collection [16], [17].

To tackle this, different research groups across developing countries have undertaken various stages of waste assessment to determine the average units of waste generated from healthcare facilities. Estimates in Macedonia found that the average rates of medical wastes calculated amongst nine different hospitals ranged between 0.5 to $1.2 \mathrm{~kg} /$ patient/day, thus totalling an average measurement of approximately 198 $\mathrm{kg} /$ day [17]. In that study, it was suggested that there was a linear correlation between the per capita healthcare wastes produced per day and the number of beds for all general hospitals, with a spearman Rank-order Coefficient $\left(\mathrm{r}_{\mathrm{s}}\right)$ of 0.945 [17]. In the Indian city, Bangladesh, a nearly 2,500 $\mathrm{kg}$ /day of healthcare waste was produced in Chittagong Medical College Hospital for which $0.57 \mathrm{~kg} /$ patient/day was produced whereby a positive correlation was established with the number of beds, rs $=0.8, \mathrm{P}<0.01$ [19]. Also, in the Agra city of the same country, approximately $25-500 \mathrm{~kg} /$ patient/day of healthcare waste was reportedly generated from three prominent hospitals at the hospital district [20].

Analysis within major cities in African countries like Hawassa, Ethiopia, revealed a healthcare waste audit of approximately $227 \mathrm{~kg} /$ patient/day [8]. In other African countries like Tanzania, the rate at which medical waste is generated was measured at between 2,000-2,500 kg/day for which 1.8-2.0 kg/patient/day was determined at Amana and Ligula districts [21].

In Nigeria, waste assessment from government hospitals is still sparse as sufficient information about the rate of generation per patient is not available for most state hospitals. In the south western region; Ibadan, the capital city of Oyo state, a recent study revealed that between $0.37-1.25$ $\mathrm{kg} /$ patient/day was being generated amongst 21 public hospitals selected at random [22]. Whilst appraising the rates of waste generation across different units in hospitals is sparse among the different states in Nigeria, independent variables would also serve to establish linear relationships between patient numbers and rates of generation in attempt to determine the efficacy of waste treatment measures in place or required [12], [23].

Previous research efforts reviewed the general effectiveness of medical waste incinerators on air particle emissions and heavy metals released to the environment post treatment from amassed healthcare waste from the Federal
Medical Center, Keffi, in Nasarawa state of Nigeria [24].

Although both the medical waste management practices and problematic areas in this center appear to be similar to others across the different states in the country, identification of the waste traffic per ward varies from state to state.

\section{Materials and Methods}

The study was conducted at the Federal Medical Centre, Keffi, Nigeria with a bed capacity of 600 . Acquisition of medical waste data was obtained by separately weighing waste at each of the 14 wards/units, namely Accident \& Emergency (A\&E), Men Medical Ward (MMW), Female Medical Ward (FMW), Female Surgical Ward (FSW), Paediatric Ward (PED), Orthopaedic Ward (ORTH), Lying in Ward (LIW), Amenity Ward (AME), Main Theatre (MT), Paediatric Surgical Ward (PSW), Intensive Care Unit (ICU), Pharmacy Unit (Pharm), Medical Laboratory (Lab), and Labour Room (LR) [25].

The measurement period was from August to September 2015. Weight measurements were performed daily over approximately 4 weeks (from Monday to Sunday) of the above period, so that the sample size was 27 days. Each day all medical waste collected were measured and recorded, covering date, shift, category of waste and quantity in $\mathrm{kg}$. The staff who took over the night shift continued with empty receptacles. Before exchanging the shift, medical waste generated from night shift were handed over to the day shift section staff. Each day during afternoon around $6.00 \mathrm{pm}$. Mean and standard deviation were used to determine the variation in the per capita waste generation amongst the different units in the Federal Medical Centre Keffi, Nassarawa state, Nigeria.

\subsection{Data Collection}

Approval to conduct the study was first obtained from the Nassarawa State Ministries of Health and Environment as well as from members of the medical center's waste management committee. Waste audits and the use of questionnaires were employed to determine patient perception aligned to finance, hospital size, medical staff manpower, waste characterization, assessment of medical waste management practice, social and cultural influence.

\subsection{Statistical Analysis}

Statistical analysis was done using SPSS Software. Spearman correlations was deduced among certain grouped sections of the medical facility.

\section{Results}

\subsection{Classification of Healthcare Wastes Generated}

The estimated percentage of healthcare waste generated from the medical center revealed a daily rate, ranging between $26.47-30.53 \mathrm{Kg}$ /day, averaging 28.5 $\mathrm{Kg} /$ Patient/Day; the majority of which was general non- 
hazardous waste $(33.6 \%)$, infectious $(21.3 \%)$, pathological (18.0\%), sharp objects $(15.8 \%)$ and pharmaceuticals $(11.4 \%)$ respectively (Figure 1).

\subsection{Total Per Capita Waste Generation Assessment}

The different wards generate separate magnitudes of waste

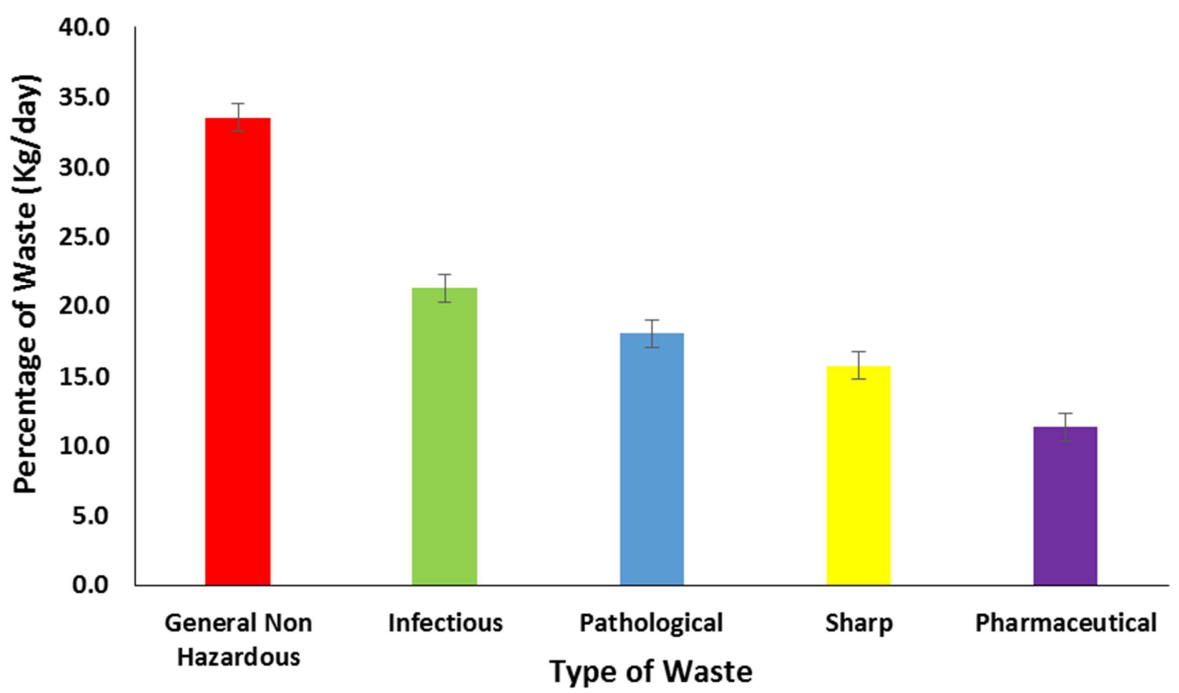

Figure 1. Percentage of pathological, infectious, pharmaceutical, general and sharp waste in the total HCW stream.

Table 1. Per capita waste generation of hazardous medical waste.

\begin{tabular}{|c|c|c|c|c|}
\hline \multirow{2}{*}{ Units/Wards } & \multicolumn{4}{|c|}{ Volume of Waste Generation } \\
\hline & Kg/Day & Kg/Week & Kg/Month & Percent (\%) \\
\hline $\mathrm{A} \& \mathrm{E}$ & $1.97 \pm 0.55$ & $13.3 \pm 0.60$ & $53.20 \pm 0.57$ & 6.92 \\
\hline MMW & $2.27 \pm 0.71$ & $15.35 \pm 0.68$ & $61.40 \pm 0.73$ & 7.98 \\
\hline FMW & $1.71 \pm 0.43$ & $11.58 \pm 0.38$ & $46.30 \pm 0.41$ & 6.02 \\
\hline FSW & $1.79 \pm 0.57$ & $12.10 \pm 0.59$ & $48.40 \pm 0.61$ & 6.29 \\
\hline PED & $1.98 \pm 0.54$ & $13.38 \pm 0.52$ & $53.50 \pm 0.48$ & 6.96 \\
\hline ORTH & $2.11 \pm 0.66$ & $14.25 \pm 0.72$ & $57.00 \pm 0.69$ & 7.41 \\
\hline LIW & $1.91 \pm 0.56$ & $12.90 \pm 0.59$ & $51.60 \pm 0.57$ & 6.71 \\
\hline AME & $1.42 \pm 1.09$ & $9.60 \pm 1.11$ & $38.40 \pm 1.07$ & 4.99 \\
\hline MT & $2.53 \pm 1.07$ & $17.05 \pm 1.05$ & $68.20 \pm 1.10$ & 8.87 \\
\hline PSW & $1.17 \pm 0.85$ & $7.93 \pm 0.87$ & $31.70 \pm 0.88$ & 4.12 \\
\hline ICU & $0.41 \pm 0.61$ & $2.80 \pm 0.56$ & $11.20 \pm 0.59$ & 1.46 \\
\hline Pharm & $2.03 \pm 0.87$ & $13.70 \pm 0.88$ & $54.80 \pm 0.91$ & 7.13 \\
\hline $\mathrm{Lab}$ & $2.34 \pm 1.05$ & $15.80 \pm 1.09$ & $63.20 \pm 1.11$ & 8.22 \\
\hline \multirow[t]{2}{*}{ LR } & $4.82 \pm 0.92$ & $32.53 \pm 0.88$ & $130.10 \pm 0.93$ & 19.92 \\
\hline & 28.5 & 192.3 & 769.0 & 100 \\
\hline
\end{tabular}

Key: Accident \& Emergency (A\&E), Men Medical Ward (MMW), Female Medical Ward (FMW), Female Surgical Ward (FSW), Paediatric Ward (PED), Orthopaedic Ward (ORTH), Lying in Ward (LIW), Amenity Ward (AME), Main Theatre (MT), Paediatric Surgical Ward (PSW), Intensive Care Unit (ICU), Pharmacy Unit (Pharm), Medical Laboratory (Lab), Labour Room (LR).

\subsection{Correlations}

From the data obtained, correlations were assessed for the healthcare waste, using graphical technique, linear regression models and measured in $\mathrm{kg} / \mathrm{bed} /$ day (Figure 2). Spearman's correlation coefficient was also used to compare selected wards and units paired against each other (Table 2).

Table 2. Correlation of waste generated between paired sections of the Federal Medical Center, Keffi, August 2015.

\begin{tabular}{lll}
\hline Paired sections & Spearman's $\left(\mathbf{r}_{\mathbf{s}}\right)$ & Interpretation \\
\hline MMW-MT & 0.90 & Very strong \\
\hline
\end{tabular}

for which the highest measured daily, weekly and month rates emanated from the Labour ward; $4.8 \pm 0.92,32.5 \pm$ 0.88 , and $130.1 \pm 0.93$ respectively in comparison to the main theatre and the laboratory with recorded daily, weekly and month concentrations of $2.5 \pm 1.07,17 \pm 1.05,68 \pm 1.10$ and $2.3 \pm 1.05,16 \pm 1.09,63 \pm 1.11$ (Table 1). 


\subsection{Surveillance and Data Collection}

Recognizance survey of the Medical Centre, involving the use of questionnaires, designed to ascertain public perception of probable factors that prompt the selection of medical facilities and the type of management practice established (Table 3).

Table 3. Mitigating factors prompting selection of healthcare waste methods and facilities used at the Medical facility.

\begin{tabular}{lll}
\hline Factors & Ranking & RII \\
\hline Financial capacity & 1 & 10 \\
Ownership (Public/Private) & 2 & 9 \\
Manpower and technical know-how & 3 & 8 \\
Size of hospital & 4 & 7 \\
Number of Beds/Patient capacity & 5 & 6 \\
Waste characteristics & 6 & 5 \\
Culture and social bias & 7 & 4 \\
\hline
\end{tabular}

The factors that influenced the choice of methods and facilities used in managing the waste were indexed using a scale of 1 to 7 whereby the lower the ranking number, the higher the level of importance and the higher the index number.

\section{Discussion}

All departments and wards within a healthcare system generates varied amounts of wastes stemming from their sundry of activities. The proffered indicators for appraisal of the medical facility's waste management was the daily weight of waste per patient generated. In this study, the data obtained revealed that an average $66.4 \% \quad(28.5$ $\mathrm{Kg} /$ Patient/Day of hazardous medical waste was produced (Figure 1). The weighed amounts was within the operating parameters for the biomedical waste incinerator at the facility, designed with a throughput of more than $50-60 \mathrm{~kg} / \mathrm{hr}$ and a thermal Heat Capacity of 100000-120000 Kcal/hour. This suggests that the waste management policy at the medical center, in collaboration with its collaborator; Ecological Fund of Nigeria, had established lean parameters via adequate forecast models that catered for the waste streams generated from all measured units and wards in
Federal Medical Center, Keffi.

With the only visible approach towards segregation of medical waste being sharp objects and other general waste types at the medical center, more stringent efforts should be adopted to aid in minimizing health and safety risks to medical waste collectors and auxiliary personnel. In the advent of used syringes and other sharp object collection, the observations in this study would be of major importance in conjunction with other studies that have indicated the risk of injury to medical waste personnel during collection and disposal of used materials in regions endemic to Hepatitis, HIV, etc [26]. Improvements pertaining to the collection and disposal of such wastes using puncture-proof polyethylene bottles rather than regular receptacles for used sharp objects should be adopted.

In adherence to the medical facility's waste management policy on disposal of sharp objects, the replacement of the small sharp containers with the puncture-proof polyethylene bottles, coupled with timely replacement once such bottles are filled up to three quarters, would ensure no incidence of sharp injuries to the personnel involved.

Furthermore, from the site visits and data obtained (figure 1, Table 1), sustainable provision of colour-coding bag systems would greatly enhance the segregation, collection, autoclaving and incineration of medical waste, i.e., green for pharmaceuticals, red bags for hazardous (infectious and pathological) wastes, yellow for mucky bed linens, etc. In line with this, each ward should be furnished with its own independent autoclave for the disinfection of reusable materials to eliminate excess waste for disposal thereby also reducing exposure to risk. With the established daily waste stream averaging $28.5 \mathrm{Kg} /$ Patient/Bed as well as the means of collection, the obvious risk identified emanated from the operators of the incinerator and storage area where the collected waste receptacles were being kept prior to incineration.

During the course of this study, it was discovered that the operators of the rotary kiln incinerator was exposed to ergonomic hazards, excess heat/noise, foul odours emanating from the collection bags stored from a few hours to days whilst building up the overall quantity to maximize incinerator operation, etc.

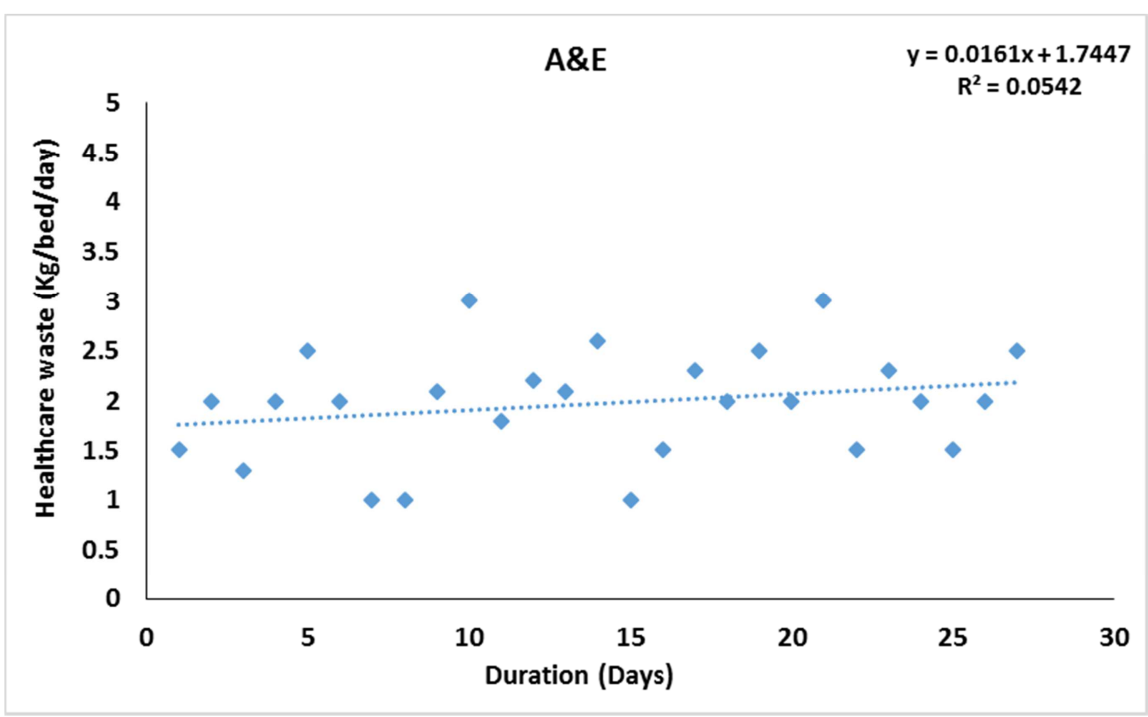



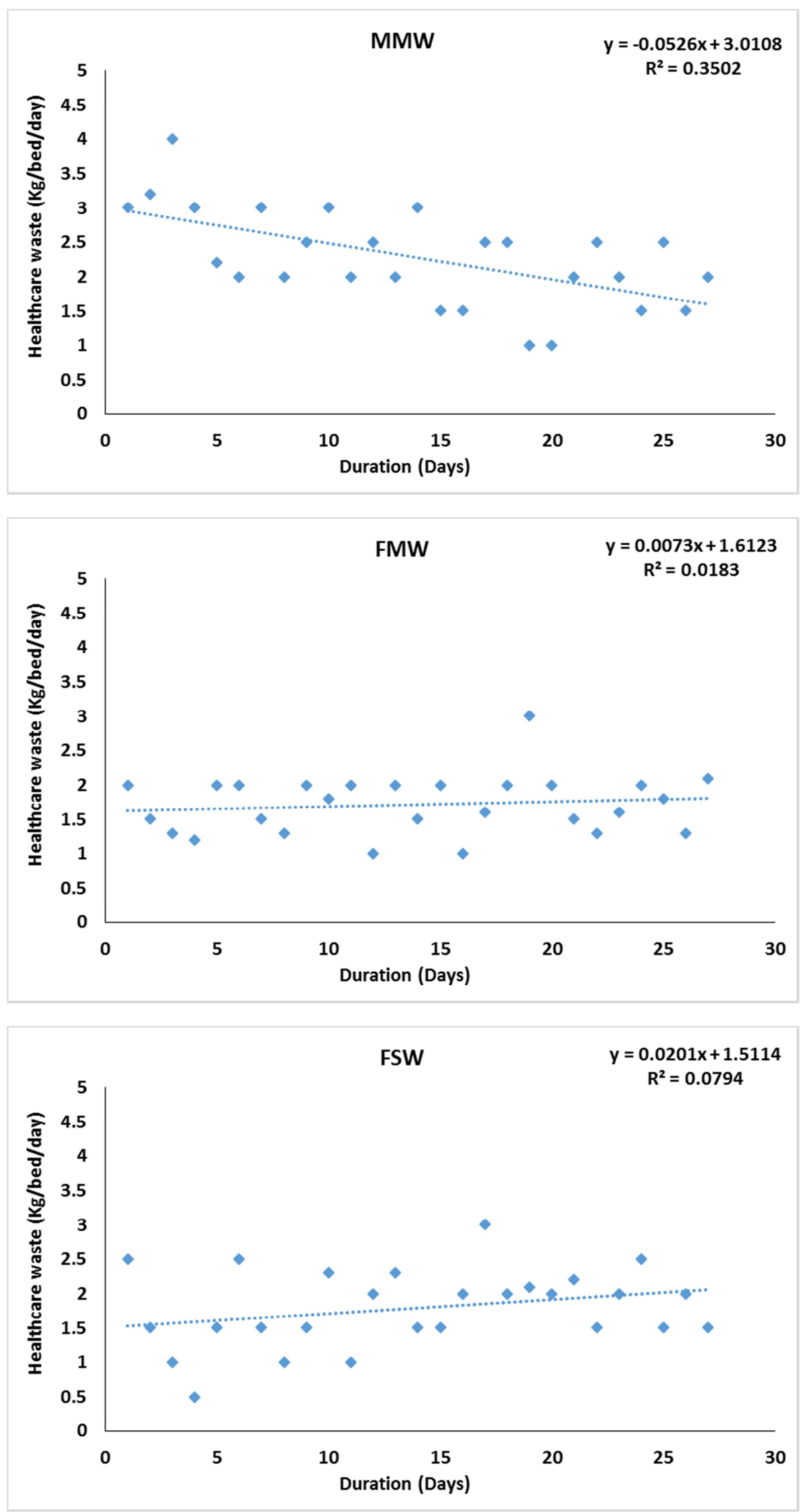

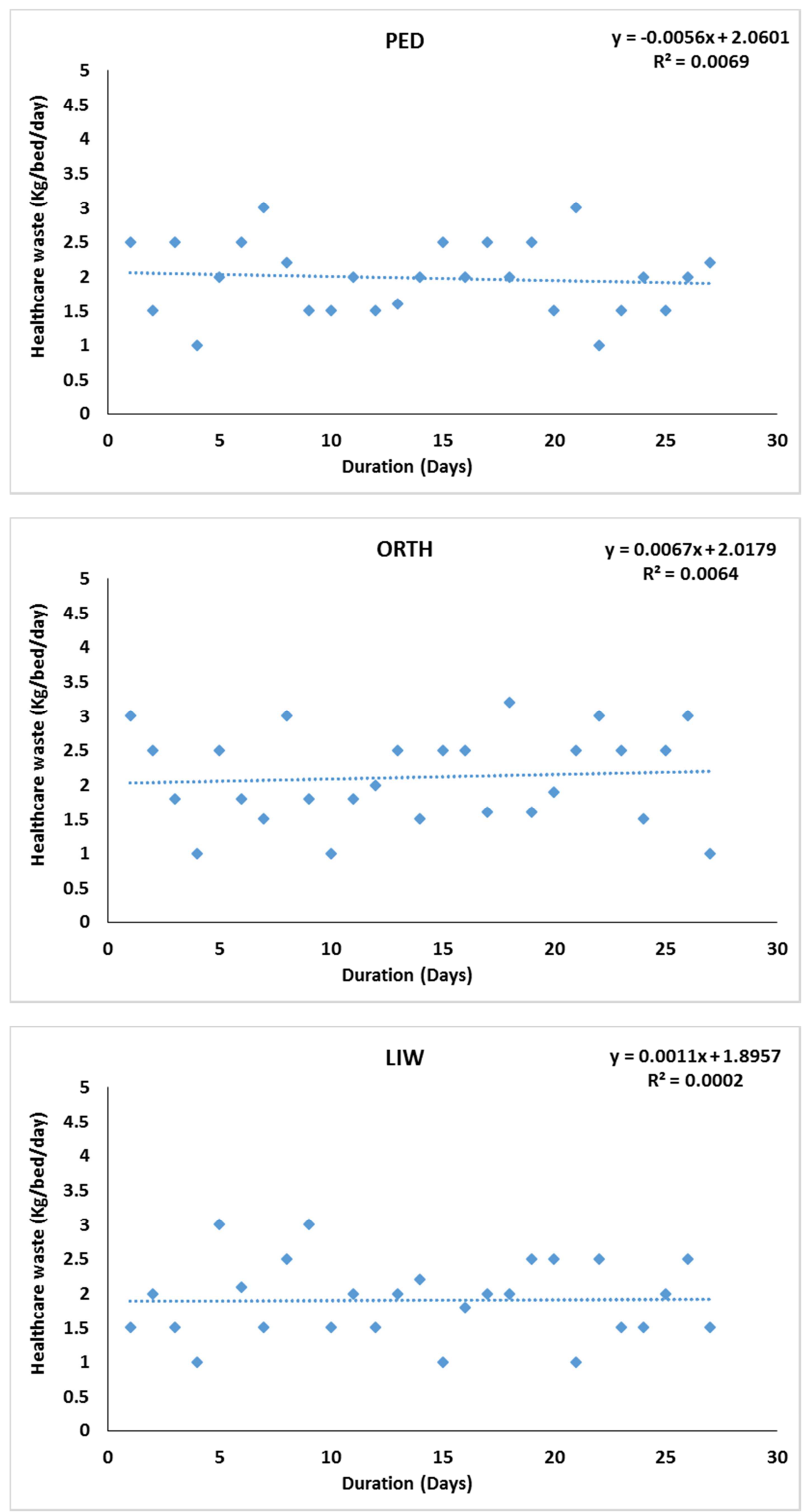

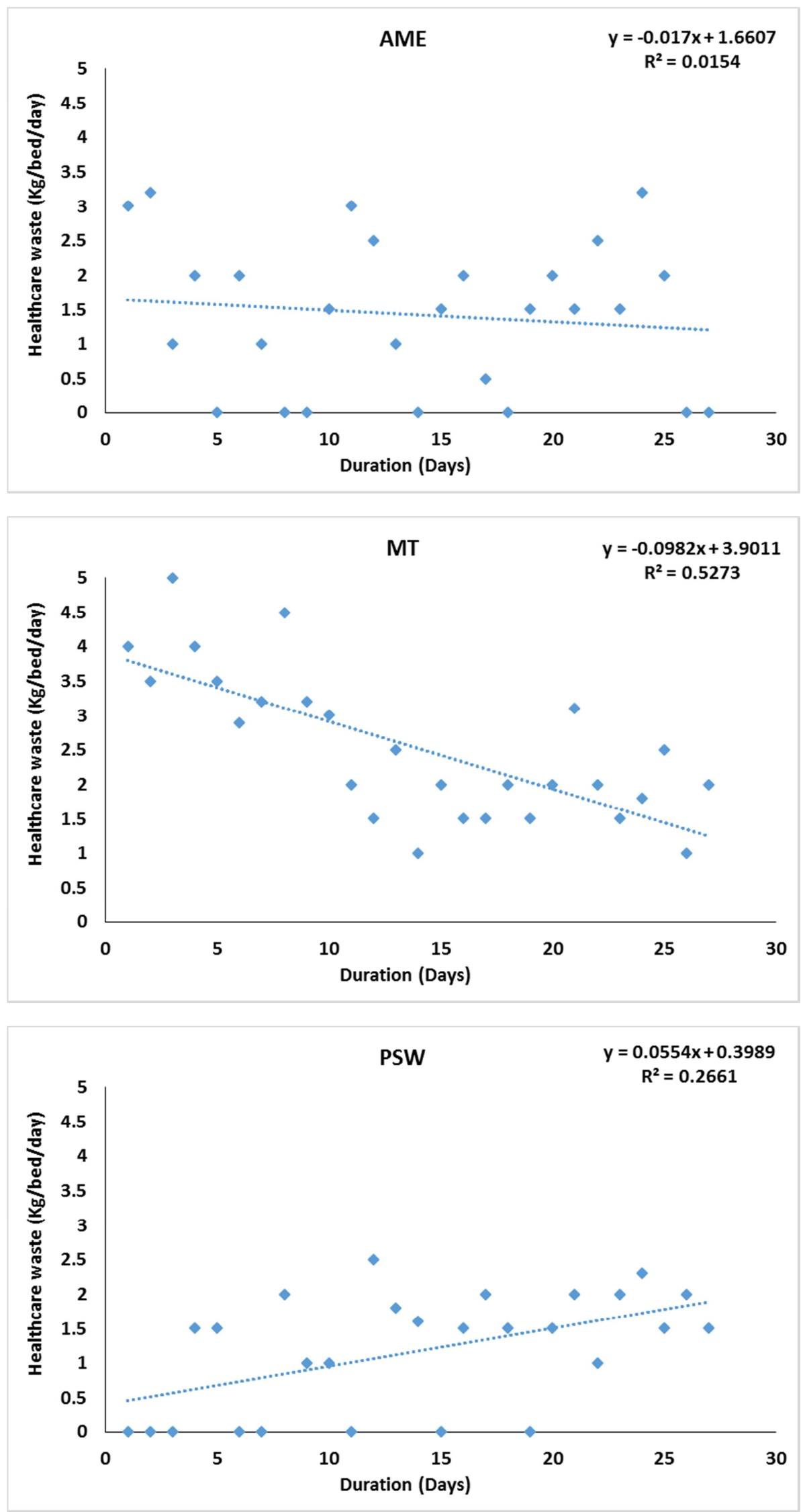

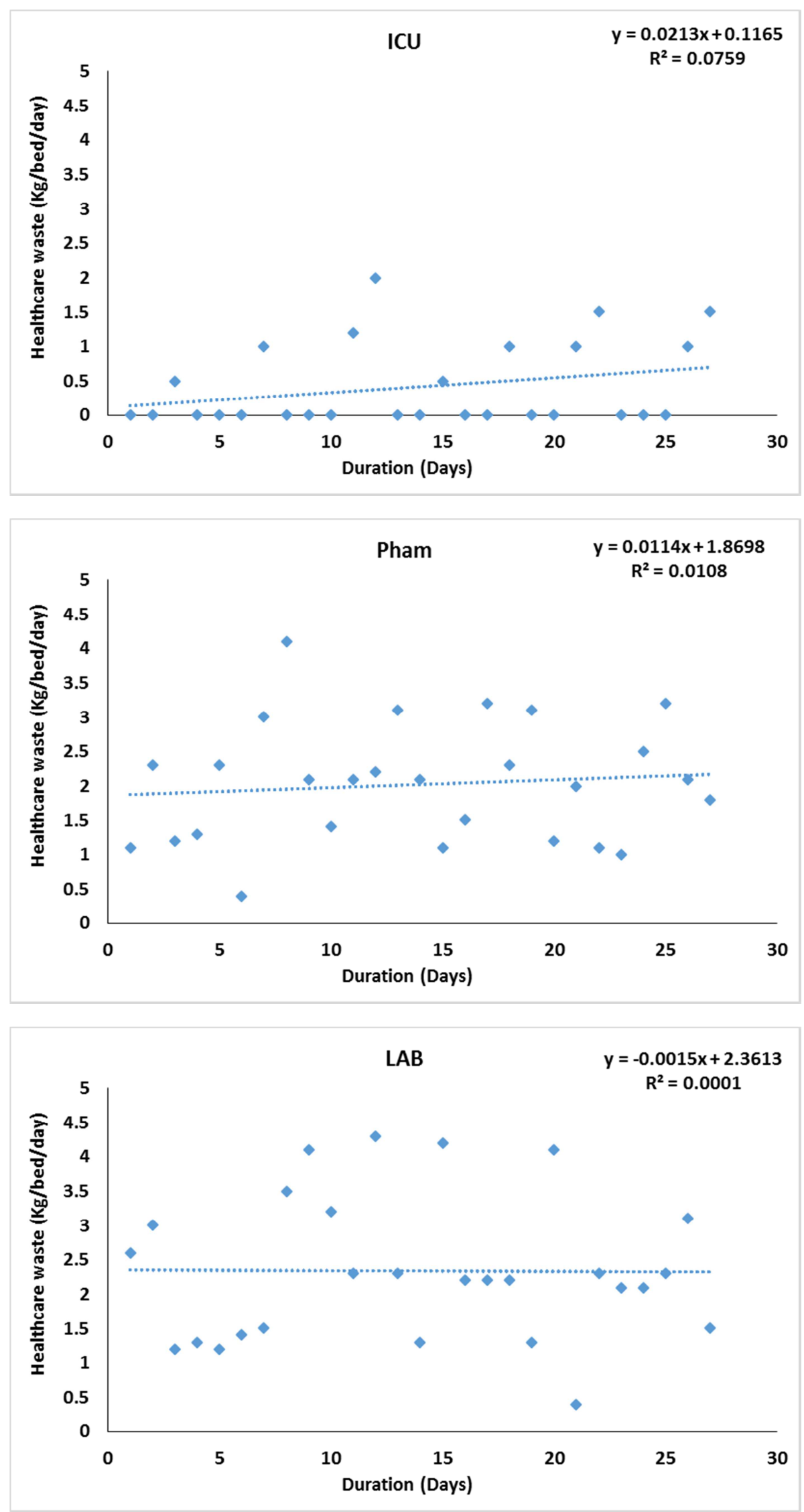


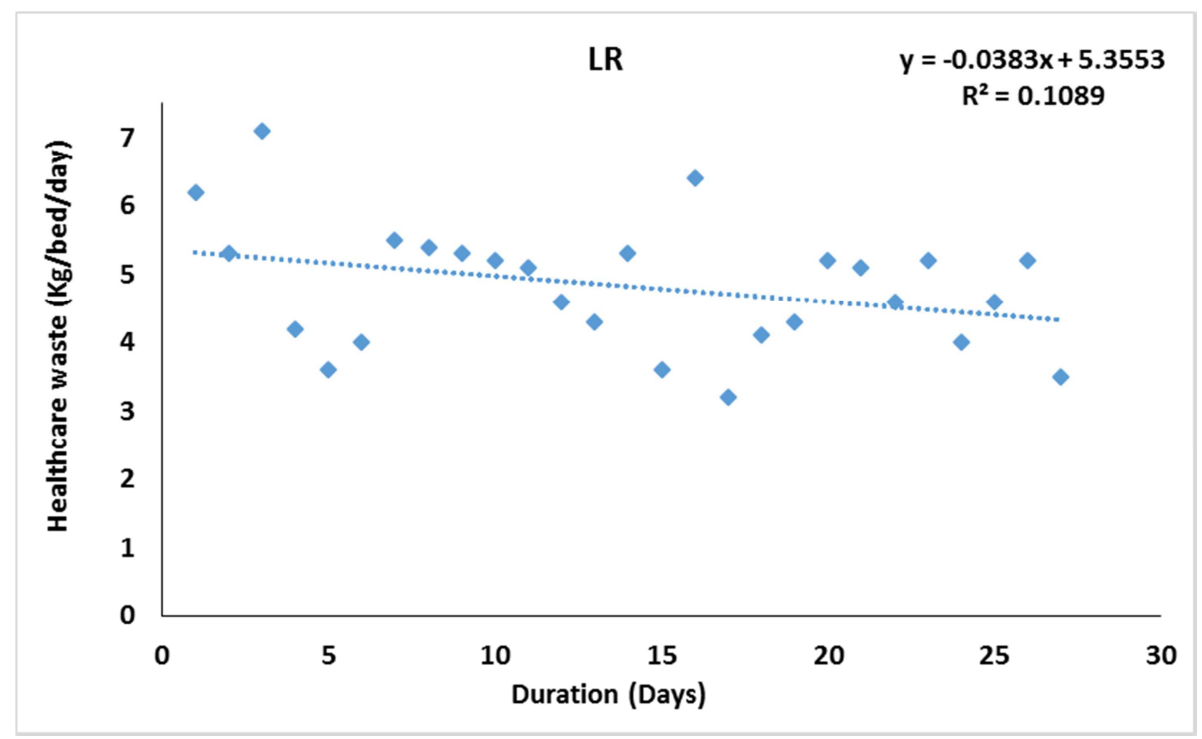

Figure 2. Healthcare waste generated daily among 14 different wards and units at the Federal Medical Center.

In this study, the total volume of waste generated per patient per week and month was found to be $192.3(\mathrm{~kg} /$ week) and $769.0(\mathrm{~kg} / \mathrm{month})$ for all 14 units/wards investigated (Table 1). The highest values of per capita waste recorded from the labour room; $4.82 \pm 0.92,32.53 \pm 0.88$ and $130.10 \pm$ $0.93 \mathrm{~kg}$ per patient per day, week, month respectively. The overflow of waste generated from the labour ward (19.92\%) is suggestive of the reproductive rate in the region. With this in mind, the population of infants and pre-adolescents would form the highest demographic in the region, thereby quantifying the data obtained from the pediatric $(1.98 \pm 0.54$, $13.38 \pm 0.52$ and $53.50 \pm 0.48 \mathrm{~kg}$ per patient per day, week, month) and pediatric surgical wards $(1.17 \pm 0.85,7.93 \pm 0.87$ and $31.70 \pm 0.88 \mathrm{~kg}$ per patient per day, week, month), as such children would require medical attention at one point or another.

The generated waste data obtained from the main theatre $(8.87 \%) ; 2.53 \pm 1.07 \mathrm{~kg}$ per patient per day, laboratory $(8.22 \%) ; 2.34 \pm 1.05 \mathrm{~kg}$ per patient per day), male ward $(7.98 \%) ; 2.27 \pm 0.71 \mathrm{~kg}$ per patient per day, orthopedic (7.41\%); $2.11 \pm 0.66 \mathrm{~kg}$ per patient per day, as well as the accident and emergency unit (6.92\%); $1.97 \pm 0.55 \mathrm{~kg}$ per patient per day all point to the need for waste management policies and practices that can accommodate higher volumes than that discovered in this study as different factors could lead to the increase of infectious and or hazardous materials, such as higher rates of road accidents, sports injuries, violent ethnic clashes and land disputes, to the outbreak of diseases like ebola, cholera, lassa fever, etc.

Graphical techniques employed in this study to illustrate the daily volumes of waste generated from each section of the healthcare facility over the duration of study revealed clear linear trends for all units and wards (Figure 2). The exclusion of an intercept in all the graphical illustrations, as well as the positive statistically significant values $\left(\mathrm{R}_{2}\right)$, suggests that wastes were not expected on days and in wards, units or departments that did not have patients. Also, the number of beds occupied can be employed as a useful predictor of healthcare waste generated from the Federal Medical Facility, Keffi. All $\mathrm{R}_{2}$ values obtained from the linear equations were statistically significant at $p<0.05$; as the data was distributed uniformly within the range of time.

With segregation of medical operations into male, female, adolescence, trauma level and degree of medical analysis, it is conceivable to group and compare certain hospital sections, thereby establishing a link that reflects the waste stream burden to the peculiar categories. Such sections include the male medical ward (MMW) and the main theatre (MT), female medical ward (FMW) and the female surgical ward (FSW), etc (Table 2). Using Spearman's correlation coefficient, this study observed a mostly very strong waste correlation amongst ten sections of the facility paired against each other, a strong correlation between the pharmaceutical and laboratory waste, as well as a moderate correlation between the intensive care unit (ICU) and the labour room (LR) depicted in Table 2.

The development and ensured sustainability of any waste management practice for both municipal solid or medical waste, is swayed by critical factors which include but are not limited to cultural and social bias, waste characterization, financial prowess, ownership of hospital (government or private), and size of hospital, etc (Table 3 ). In this study, it was established that the primary factor that governed the management of healthcare wastes were financial capacity emanating from both hospital management as well as the visiting populace, per capita waste generation and the size of each ward per bed space (Table 3). From the survey performed in this study, cultural and social bias was found to be the least impeding factor thus suggestive of the region's acceptance of waste management policies introduced by the government outfit for which the sole responsibility of its implementation was that of the hospital workers. This then validates the findings that financial capacity by way of funding the operations and maintenance of the waste 
management process (colour coded bags, incinerator, electricity/energy for the equipment involved, disinfectants and other cleaning consumables) was the most important factor affecting the medical centre's waste management practice [22].

\section{Conclusion}

Data obtained in this study depicts vital information useful to medical waste management decision makers as well as healthcare personnel to expedite development and enhancement of healthcare waste management framework. Study done has established a database of information and statistics on medical waste management from generation to final disposal. Actual measured medical waste generation data has been properly recorded its components, composition, and quantities, then analyzed to have information's that will form the basis for realistic planning, designing, budgeting and implementation of medical waste management procedures that will be economical, effective and efficient. Data obtained in this study has shown that the daily, weekly and monthly rate of waste generation from all 14 studied sections totalled 28.5 (Kg/day/person), 192.3 (Kg/week/person) and 769.0 (Kg/month/person). The highest percentage waste emanated from the labour room (19.92\%) and the least was from the intensive care unit $(1.46 \%)$. Infectious waste topped the overall hazardous waste stream (21.3\%), pathological $(18.0 \%)$, sharp objects $(15.8 \%)$ and pharmaceuticals $(11.4 \%)$ respectively. Correlations from paired units and wards revealed a very strong correlation between 10 out of 14 sections of the center.

\section{References}

[1] Diaz L. F., Eggerth L. L., Enkhtsetseg Sh., and Savage G. M., (2005). Characteristics of healthcare waste. Waste Management, 28: 1219-1226.

[2] Cheng Y. W., Sung F. C., Yang Y., Lo Y. H., Chung Y. T., and Li K. C., (2009). Medical waste production at hospitals and associated factors. Journal of Waste Management, 29: 440444.

[3] Muduli K., and Barve A., (2012). Barriers to green practices in healthcare waste sector: an Indian perspective. International Journal of Environmental Science and Development, 3: 393-399.

[4] Rahim F. L. M., Hassim M. H., and Mokhtar M. M., (2015). Environmental Assessment of Ashes Generated From Medical Waste Incineration. Chemical Engineering Transactions, 45: 1699-1705.

[5] Cheng Y. W., Sung F. C., Yang Y., Lo Y. H., Chung Y. T., and Li K. C., (2008). Medical waste production at hospitals and associated factors. Waste Management, 29.

[6] Abd El-Salam M. M., (2010). Hospital waste management in El-Beheira Government, Egypt. Journal of Environmental Management, 91: 618-629.

[7] Soysal A., Simsek H., Soysal D., and Alyu F., (2010).
Management of health-carewaste in Izmir, Turkey. Annali dell'Istituto Superiore di Sanit 'a, 46: 299-302.

[8] Haylamicheal D. I., Dalvie A. M., Yirsaw D. B., and Zegeye A. H., (2011). Assessing the management of healthcare waste in Hawassa city, Ethiopia. Waste Management Research, 29: 854-862.

[9] Bokhoree C., Beeharry Y., Makoondlall-Chadee T., Doobah T., and Soomary N., (2014). Assessment of Environmental and Health Risks Associated with the Management of Medical Waste in Mauritius. APCBEE Procedia, 9: 36-41.

[10] Alhumoud J. M., and Alhumoud H. M., (2007). An analysis of trends related to hospital solid wastes management in Kuwait. Management of Environmental Quality. An International Journal, 18: 502-513.

[11] Mastorakis N. E., Bulucea C. A., Oprea T. A., Bulucea C. A., and Dondon P., (2011). Holistic approach of biomedical waste management system with regard to health and environmental risks. Development, Energy, Environment, Economics, 5: 287295.

[12] Debere M. K., Gelaye K. A., Alamdo A. G., and Trifa Z. M., (2013). Assessment of the health care waste generation rates and its management system in hospitals of Addis Ababa, Ethiopia, 2011. BMC Public Health, 13: 28-37.

[13] Vitale K., (2008). Management of hazardous medical waste in Croatia. Waste Management, 28: 1049-1056.

[14] Bilgili M. S., (2009). Medical waste management in Turkey: A case study of Istanbul. Waste Management, 29: 445-448.

[15] Cheng Y. W., Li K., and Sung F. C., (2010). Medical waste generation in selected clinical facilities in Taiwan. Waste Management, 30: 1690-1695.

[16] EUROSTAT, (2012). Statistical data on medical waste generation in Europe.

[17] Sanida G., Karagiannidis A., Mavidou F., Vartzopoulos D., Moussiopoulos N., and Chatzopoulos S., (2010). Assessing generated quantities of infectious medical wastes: a case study for a health region administration in Central Macedonia, Greece. Waste Management, 30: 532-538.

[18] Moreira A. M. M., and Günther W. M. R., (2013). Assessment of medical waste management at a primary health-care center in São Paulo, Brazil. Waste Management, 33: 162-167.

[19] Alam M., Sujauddin M., Iqbal A., and Huda S., (2008). Report: healthcare waste characterization in Chittagong Medical College Hospital, Bangladesh. Waste Management Research, 26: 291-296.

[20] Khajuria A., and Kumar A., (2007). Assessment of healthcare waste generated by Government Hospital in Agra city, India. Department of Environmental Studies, School of Life Sciences, Ambedkar University, 5: 25-30.

[21] Kagonji I. S., and Manyele S. V., (2011). Analysis of the measured medical waste generation rate in Tanzanian district hospitals using statistical methods. African Journal of Environmental Science and Technology, 5: 815-833.

[22] Wahab A. B., and Adesanya D. A., (2011). Medical Waste Generation in Hospitals and Associated Factors in Ibadan Metropolis, Nigeria. Research Journal of Applied Sciences, Engineering and Technology, 3: 746-751. 
[23] Bdour A., Altrabsheh N., Hadadin M., and Al-Shareef M. (2007). Assessment of medical waste management practice. A case study of the northern part of Jordan. Journal of Waste Management, 27: 746-759.

[24] Useh U. J., Muhammed M. A., and Useh M. U., (2017). Heavy Metal and Air Quality Assessment around a Healthcare Waste Incinerator Facility in Nigeria. American Journal of Materials Synthesis and Processing, 2: 65-70.
[25] Komilis D., Katsafaros N., and Vassilopoulos P., (2011). Hazardous medical waste generation rates in Greece: Case studies from medical facilities in Attica and from a small insular hospital, Waste Management and Research, 29: 807814.

[26] Bendjoudi Z., Taleb F., Abdelmalek F., and Addou A., (2009). Healthcare waste management in Algeria and Mostaganem department. Waste Management, 29: 1383-1387. 